\title{
Does Aromaticity in a ReACTION Product InCREASE OR DECREASE THE INTRINSIC BARRIER? KINETICS OF THE REVERSIBLE DEPROTONATION OF BENZOFURAN-3(2H)-ONE AND BENZOTHIOPHENE-3(2H)-ONE
}

Claude F. Bernasconi and Moisés Pérez-Lorenzo

Supporting Information 


\section{Table of Contents}

page

$\begin{array}{lll}\text { Figure S1 Spectrophotometric } \mathrm{p} K_{\mathrm{a}}^{\mathrm{KH}} \text { determination for 3H-O. } & \text { S3 }\end{array}$

Figure S2 Reaction of $\mathbf{3 H - O}$ with piperidine. $\quad$ S4

Figure S3 Reaction of 3H-O with piperidine. Plot of slopes versus $\mathrm{a}_{\mathrm{H}^{+}}$according $\quad$ S5 to eq 9.

Figure S4 Reaction of 3H-O with glycinamide. Plot of slope ${ }^{-1}$ versus $\mathrm{a}_{\mathrm{H}^{+}}^{-1} \quad$ S6 according to eq 11 .

$\begin{array}{lll}\text { Figure S5 } & \text { Reaction of } \mathbf{3 H}-\mathbf{S} \text { with HEPA. } & \text { S7 }\end{array}$ 


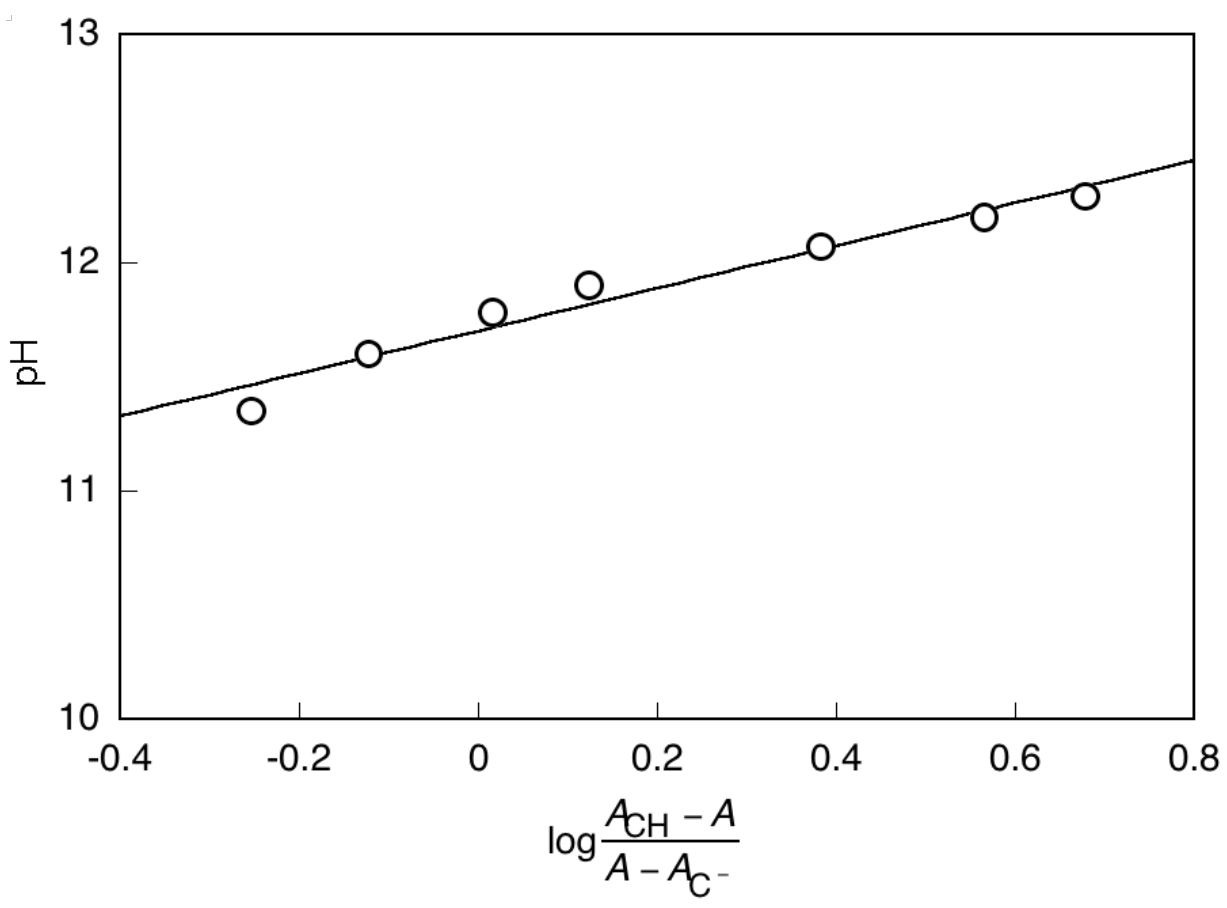

Figure S1. Spectrophotometric $\mathrm{p} K_{\mathrm{a}}^{\mathrm{KH}}$ determination for $\mathbf{3 H - O}$. 


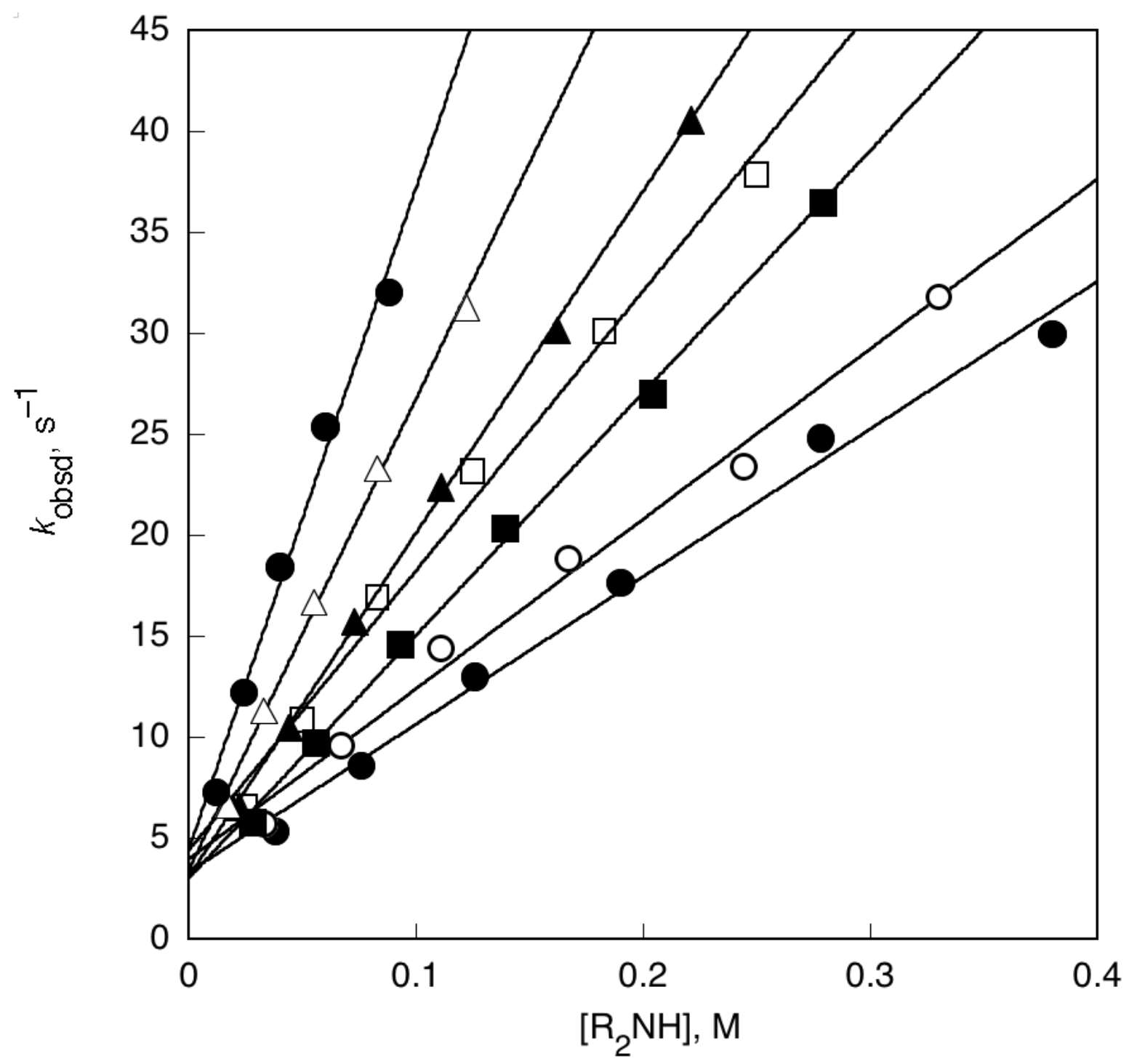

Figure S2. Reaction of 3H-O with piperidine: J, pH 10.89; C, pH 11.09; H, pH 11.29; G, pH 11.39, B, pH 11.49; E, pH 11.69; J, pH 11.89. 


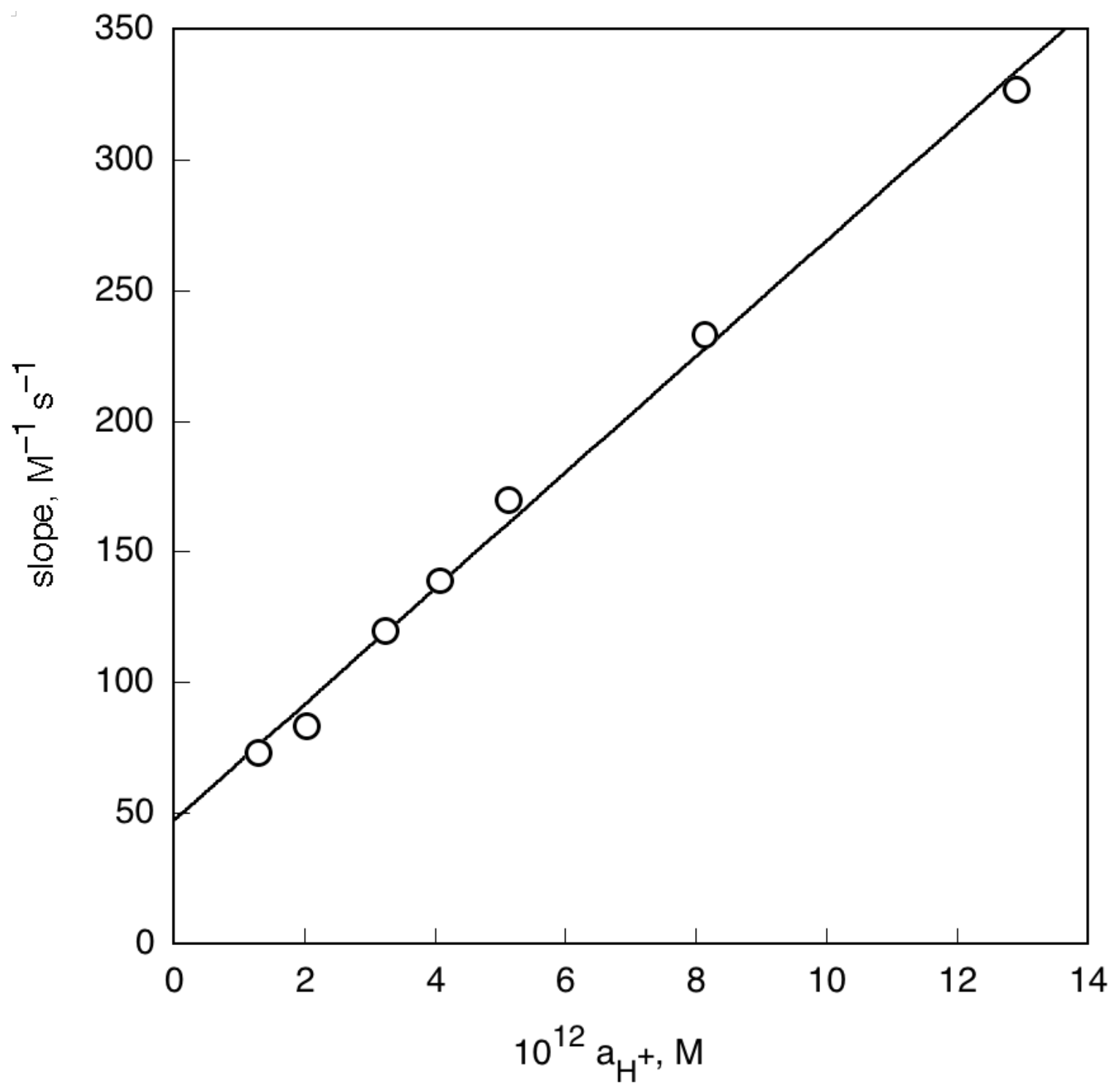

Figure S3. Reaction of $\mathbf{3 H}-\mathbf{O}$ with piperidine. Plot of slopes versus $\mathrm{a}_{\mathrm{H}^{+}}$according to eq 10 . 


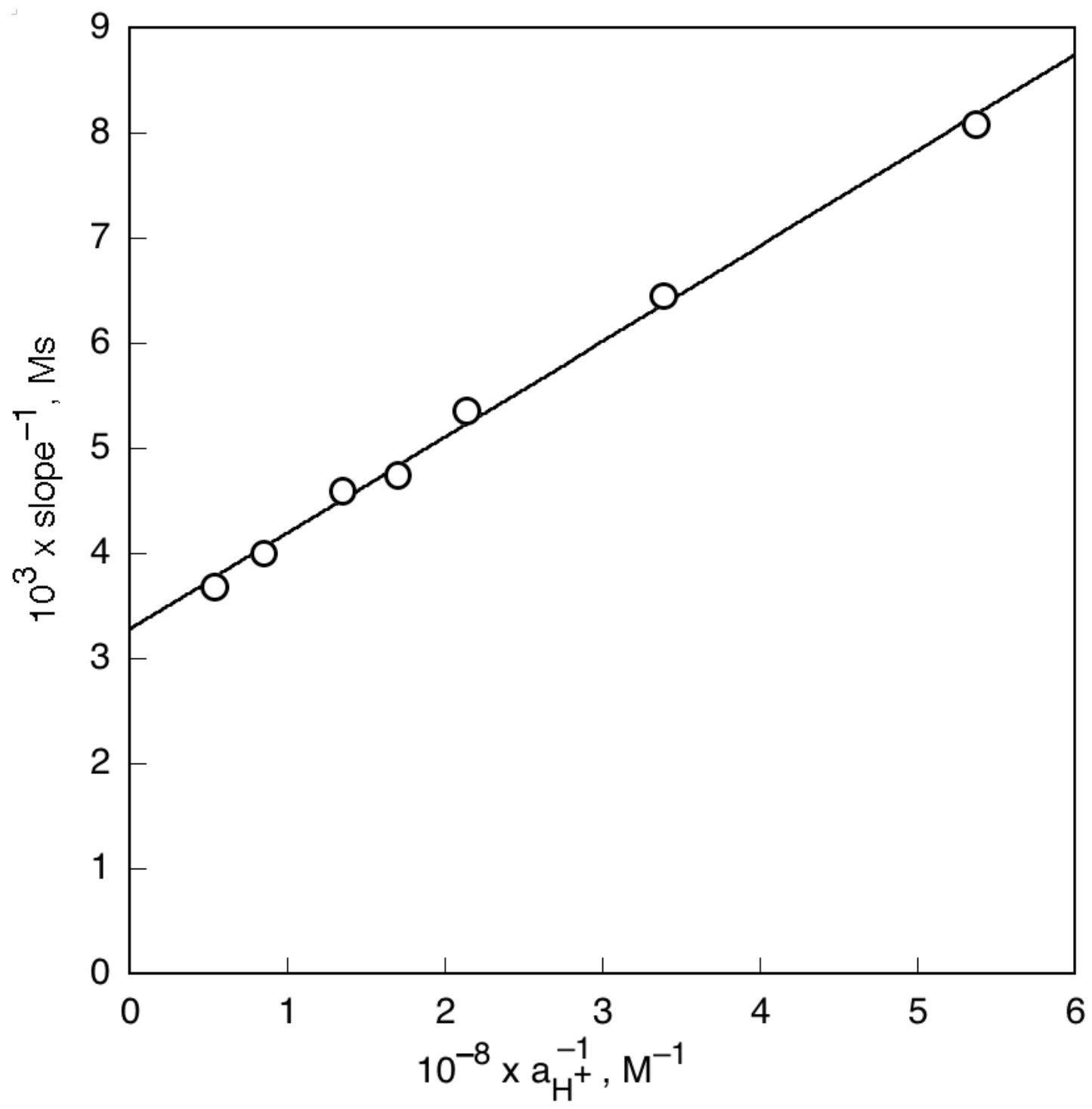

Figure S4. Reaction of $\mathbf{3 H - O}$ with glycinamide. Plot of slope ${ }^{-1}$ versus $\mathrm{a}_{\mathrm{H}^{+}}^{-1}$ according to eq 12 . 


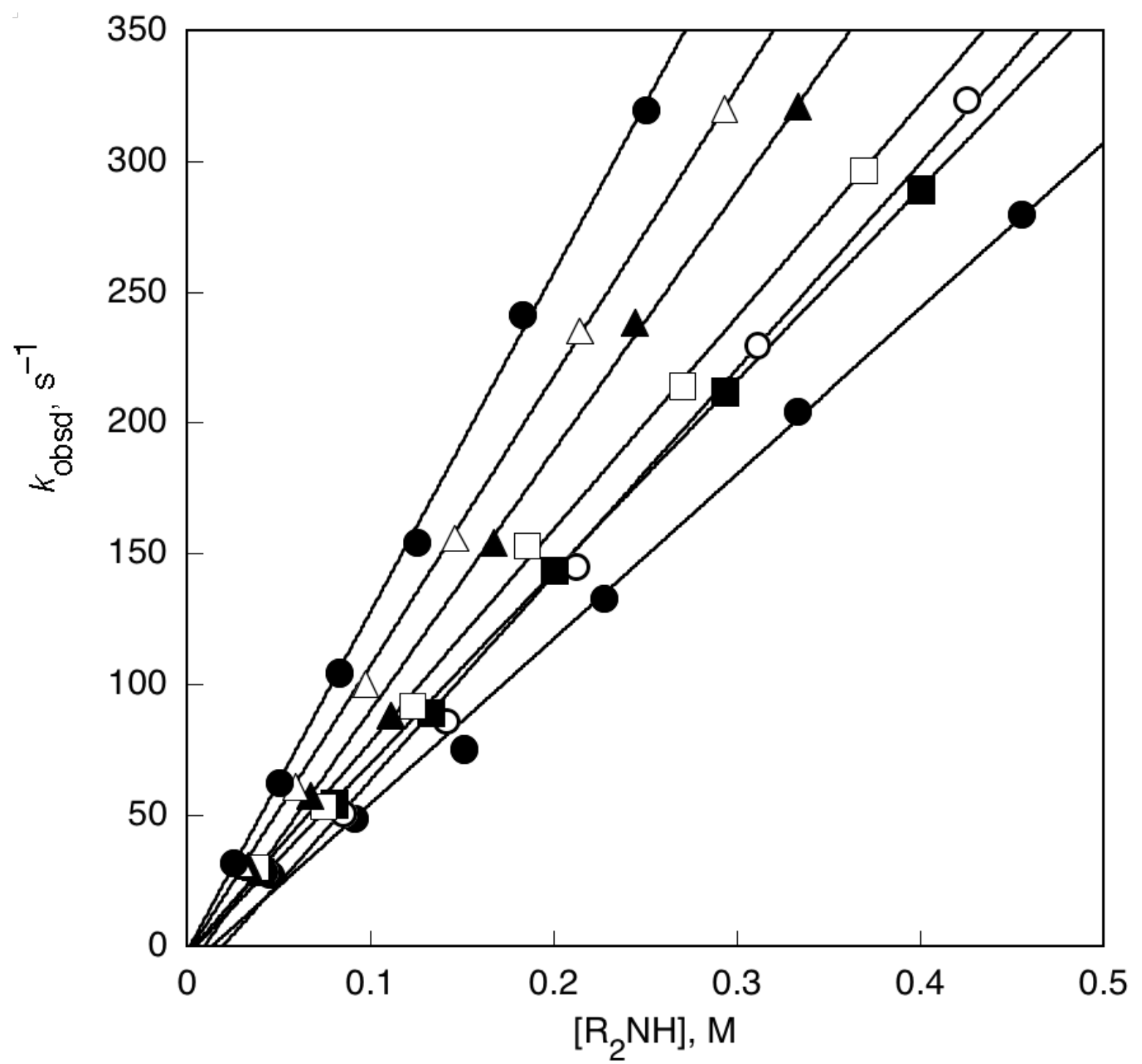

Figure S5. Reaction of 3H-S with HEPA: J, pH 9.43; C, pH 9.58; H, pH 9.73; G, pH 9.88, B, pH 10.03; E, pH 10.18; J, pH 10.43. 